\title{
Aoristo)))))
}

International Journal of Phenomenology, Hermeneutics and Metaphysics

\section{Necessidade metafísica e distanciamento social por pandemía: uma perspectiva schopenhaueriana}

\author{
Metaphysical need and social distancing for pandemic: \\ a Schopenhauerian perspective
}

\author{
Prof. Dr. Arthur Grupillo \\ Universidade Federal de Sergipe' \\ Prof. Ms. Matheus Freitas \\ Universidade Federal de Sergipe ${ }^{2}$
}

\section{RESUMO}

Este artigo toma como ponto de partida as reflexões de Schopenhauer sobre um traço distintivo do ser humano, e que ele define como "necessidade metafísica". Uma espécie de disposição natural para colocar questões que ultrapassam a esfera empírica e que só podem ser respondidas pela filosofia ou pela religião. Segundo ele, duas condições não podem faltar ao exercício metafísico: o espanto e a introspecção. Sendo assim, perguntamos se a pandemia de COVID-19 e o distanciamento social praticado por causa dela podem corresponder ou ser favoráveis a estas duas condições, promovendo assim, de algum modo, a filosofia e a religião. Se isso é plausível, fatores sociais poderiam contribuir diretamente para as disposições de ânimo associadas à atividade filosófica e religiosa. Além disso, perguntamos também, agora em sentido contrário, sobre as consequências sociais desse exercício, os efeitos da filosofia e da religião sobre a sociedade em situação de pandemia.

\section{PALAVRAS-CHAVE}

Necessidade metafísica; filosofia; religião; distanciamento social; pandemia

\footnotetext{
${ }^{1}$ E-mail: aegrupillo@gmail.com . Orcid: https://orcid.org/0000-0001-5273-6990

2 E-mail: silvafreitasmatheus@hotmail.com
} 


\title{
Aoristo)))))
}

\author{
International Journal of Phenomenology, Hermeneutics and Metaphysics
}

\begin{abstract}
This article takes as his starting point the reflections of Schopenhauer on a distinctive trait of human being, which he defines as "metaphysical need". It is a kind of natural disposition to raise questions which goes beyond the empirical domain and could only be answered by philosophy or religion. According to him, two conditions are necessary to the metaphysical exercise: wonder and introspection. Therefore, we ask if the COVID-19 pandemic and the social distancing practiced because of it correspond or are favorable to these conditions, thereby promoting philosophy and religion in some extent. If this is so, social factors could contribute directly to the moods associated to philosophical and religious activity. Moreover, we also ask, now in the opposite direction, about the social consequences of this exercise, that is, the effects of philosophy and religion on a society in pandemic situation.
\end{abstract}

\section{KEYWORDS}

Metaphysical need; philosophy; religion; social distancing; pandemic

Trata-se, neste artigo, de investigar, na perspectiva do filósofo Arthur Schopenhauer e sua doutrina da Vontade, as consequências metafísicas do distanciamento social, praticado durante a pandemia de COVID-19 em praticamente todo o mundo. Um traço distintivo dos seres humanos, destacado por Schopenhauer (2015b, p. 200), é a sua "necessidade metafísica" (metaphysische Bedürfniß), espécie de carência por um "conhecimento que vai mais além da possibilidade da experiência"; certa ânsia por saber algo "sobre aquilo que se esconde atrás da natureza e a torna possível". Neste sentido, cada um de nós é, para Schopenhauer (2015b, p. 195), um animal metaphysicum, uma criatura que se pergunta pelo seu lugar no mundo e a que propósito supremo servem suas obras.

Mas, segundo o filósofo, duas condições são indispensáveis para a reflexão metafísica: o espanto (Verwunderung) e a introspecção. (Besinnung) O primeiro é o ponto de partida da metafísica, despertado nas pessoas pela "consciência em face da morte"; consciência manifestada de variadas maneiras, desde a suposição inevitável de que a sua vida é finita até o sentimento de que todo esforço, contra esse imperativo, é vão. (SCHOPENHAUER, 2015b, p. 195) Mas, de modo algum o espanto esgota as condições da atividade metafísica. Sem a introspecção, é infértil. Ou, melhor ainda, a introspecção é o que permite ao ser humano não só espantar-se como também elaborar reflexivamente seu espanto: "no ser humano, a essência íntima da natureza chega pela primeira vez à introspecção: então espanta-se com as próprias obras e pergunta-se o que ela mesma é". (SCHOPENHAUER, 2015b, p. 195) Por isso, o espanto vem condicionado, no indivíduo, pelo desenvolvimento da inteligência, e também pelo "saber em torno da morte", que, por sua vez, estimula a introspecção. Espanto parece ser, então, a consciência da morte, enquanto a introspecção, o seu saber; e ambos parecem andar sempre juntos como condição da metafísica. 


\section{Aoristo)))))}

\section{International Journal of Phenomenology, Hermeneutics and Metaphysics}

Não obstante, a necessidade metafísica é simplesmente natural desse animal que é o homem, mesmo nos homens de pouco saber; não apenas os livros de filosofia, mas também "templos e igrejas, pagodes e mesquitas, em todos os países, em todos os tempos, no esplendor e na grandeza, testemunham a necessidade metafísica do ser humano, necessidade que, forte e inextirpável, pisa os calcanhares da necessidade física". (SCHOPENHAUER, 2015b, p. 197) E, se é possível pensar que falta aí introspecção, no sentido de reflexão ou inteligência, certamente não é possível dizer que se tem aí menos consciência ou se sabe menos da morte. Contudo, nem toda necessidade metafísica "anda de mãos dadas com a capacidade metafísica [metaphysische Fähigkeit]”. (SCHOPENHAUER, 2015b, p. 197, itálico nosso) Aquela que se contenta com "fábulas sem graça", ou que, consciente da morte, a despreza e mesmo entusiasma a "sangrentas guerras" e às mais "amplas conquistas", parece, enquanto sacia a carência metafísica, redundar na mais desesperada perseguição da carência física. (SCHOPENHAUER, 2015b, p. 197) Às vezes, para o filósofo, encontramos metafísicas arbitrárias e mesmo mal-intencionadas. Deve ser possível distinguir, assim, segundo Schopenhauer (2015b, p. 200), um exercício inadequado nas disciplinas da filosofia ou da religião, posto que também as considera como as duas únicas espécies de metafísica, presentes em todos os "povos civilizados". Mas, sendo a metafísica uma necessidade natural do animal racional, e o espanto e a introspecção, suas condições necessárias, haveria maneira de promover ou estorvar essas condições, consequentemente estimulando ou embotando tal disposição natural?

Responder afirmativamente a esta pergunta significa, ao mesmo tempo, encontrar uma maneira produtiva para abordar o problema aqui proposto. Em primeiro lugar, Schopenhauer (2015b, p. 196) afirma que há uma "capacidade" de nos espantarmos. Mas isso de um modo diferente para cientistas e filósofos. Enquanto "a disposição filosófica propriamente dita consiste, antes de tudo, na capacidade de nos espantarmos diante daquilo que é o comum e cotidiano", os cientistas "espantam-se tão somente com escolhidas e raras aparências". O espanto do filósofo é o espanto com o comum, o que lhe permite "fazer do universal da aparência um problema nosso". A própria aparência, ou seja, que algo simplesmente aconteça é o que espanta o filósofo e que vem à tona como um problema universal. O cientista, por sua vez, tem por problema reconduzir meramente as aparências raras "às aparências mais conhecidas". Sendo assim, se uma pandemia de escala mundial sem precedentes em uma geração inteira é certamente um fato raro que, realmente, está a mobilizar cientistas de toda parte, ele não teria, a princípio, nenhum interesse especial para o filósofo. Entretanto, sabemos que a filosofia não é a única disciplina metafísica. E, além disso, sabemos que o espanto é despertado pela mera "consciência em face da morte". Haveria que se distinguir, então, entre o espanto metafísico em geral e o espanto filosófico "propriamente dito". Sabemos também que o espanto, seja ele qual for, é improdutivo sem a introspecção, esta, sim, plenamente estimulada pelo fato raro em questão; pois, sem dúvida, diz Schopenhauer (2015b, p. 196), “é o saber em torno da morte e, junto

Arthur Grupillo

Matheus Freitas

Toledo, v. 3, n’2(2020) p. 27-40 


\section{Aoristo)))))}

\section{International Journal of Phenomenology, Hermeneutics and Metaphysics}

com este, a consideração do sofrimento e da miséria da vida, o que dá mais forte estímulo para a introspecção filosófica e para a interpretação metafísica do mundo".

Portanto, se é verdade que nem todos têm aptidão para o espanto filosófico propriamente dito, todos certamente trazem consigo a consciência da morte e a necessidade metafísica. Àqueles que já apresentam a capacidade para o espanto filosófico, então, talvez este fato raro, a pandemia em si, do saber em torno da morte, do sofrimento e da miséria da vida, forneça o mais forte estímulo para a introspecção necessária à consideração metafísica do mundo. Por outro lado, os inaptos ao espanto filosófico, é provável que encontrem, se até isso não lhes for roubado por outros meios, a introspecção necessária à interpretação metafísica do mundo pela disciplina religiosa. De fato, Schopenhauer distingue duas metafísicas:

[...] a grande diferença originária dos poderes de entendimento, acrescida do exigido muito esforço relacionado ao seu cultivo, cria uma diferença tão grande entre as pessoas, que, assim que um povo sai por si mesmo do estado de rudeza, uma só metafísica não pode bastar para todos; por isso nos povos civilizados deparamo-nos invariavelmente com dois tipos distintos de metafísica, cujo diferencial é uma ter sua certificação interior a si, a outra exterior a si. (SCHOPENHAUER, 2015b, p. 200)

Os dois tipos de metafísica distinguidos por Schopenhauer nesta passagem são a filosofia e a religião. Com efeito, no tomo II dos seus Parerga e Paralipomena ele explica, na esteira de sua doutrina da Vontade, que o ser humano em geral interessa-se, primeiramente, pela satisfação de suas necessidades e prazeres físicos, e depois busca algum entretenimento e diversão. (SCHOPENHAUER, 2009, p. 340) Neste sentido, os filósofos e os fundadores das religiões viriam ao mundo para despertar a humanidade de sua letargia e "indicar-lhe o elevado sentido da vida"; os filósofos cumpririam essa tarefa dirigindo-se a poucos, e os fundadores das religiões, a muitos. Assim, podemos entender que as religiões fazem o máximo pelos naturalmente dispostos à metafísica, mas não necessariamente à filosofia; as religiões são, para eles, o principal antídoto contra a escravidão da vontade, contra a "afirmação da vontade de vida". (SCHOPENHAUER, 2009, p. 381)

Neste contexto, o distanciamento social (social distancing) recomendado pela Organização Mundial da Saúde (OMS) para refrear a transmissão já pandêmica do vírus Sar-CoV-2, e pela modelagem estatística mais influente entre os epidemiologistas (WALKER, 2020), pode ser visto, a princípio, como uma circunstância que promove as duas condições necessárias ao exercício metafísico: o espanto, pela consciência da morte, e a introspecção, pela separação física entre as pessoas. Antes, porém, mais um esclarecimento é necessário sobre o conceito de introspecção, que deve nos levar ao cerne de nossa tentativa de colocar fato tão raro sob prisma de filosofia tão incomum. Para Schopenhauer, a introspecção está ligada à necessidade metafísica, tipicamente humana, por desvincular-se da necessidade estritamente física, tipicamente animal. E 


\section{Aoristo)))))}

\section{International Journal of Phenomenology, Hermeneutics and Metaphysics}

isso significa um ponto de transição da afirmação da vontade de vida à possibilidade de sua negação.

A AFIRMAÇÃO DA VONTADE DE VIDA, que, portanto, tem o seu centro no ato de geração, é indefectível no animal. Pois só no ser humano é que a vontade, que é a natura naturans, chega à INTROSPECÇÃO. Chegar à introspecção significa: conhecer não apenas para satisfazer as necessidades momentâneas da vontade individual, para servi-la nas urgências do presente [...]. Aqui, então, a coisa torna-se grave, e impõe-se ao ser humano a pergunta sobre a origem e o fim de tudo isso, e, principalmente, se a fadiga e a miséria de sua vida, se a fadiga e a miséria de seus esforços são compensadas pelo ganho obtido. Le jeu en vaut-il bien la chandelle? - Em conformidade com tudo isso, aqui é o ponto em que, à luz de um conhecimento mais distinto, o ser humano decide-se pela afirmação ou negação da Vontade de vida. (SCHOPENHAUER, 2015b, p. 681-682 [maiúsculas do autor])

Portanto, se inevitavelmente relacionada à possibilidade de negação da vontade de vida, que no animal é imperativa, então a introspecção é, da mesma forma, avessa aos fundamentos egoístas para a formação social, tão característicos do pensamento político de Schopenhauer, amiúde comparado, neste aspecto, a Hobbes. Na verdade, a sociedade é, para ele, um problema, uma daquelas situações-limite da teoria, em que "o conflito interno da Vontade consigo mesma atinge temível manifestação". (SCHOPENHAUER, 2015a, p. 386) Isso porque, paradoxalmente, são o egoísmo e a afirmação da vontade de vida que levam à formação social e ao estabelecimento de um Estado político, que, por sua vez, necessitam, para isso, refrear o mesmo egoísmo e a mesma afirmação da vontade de vida; do contrário, a vontade implodiria num egoísmo generalizado e incontido. A sociedade existe para realizar este limite e impedir um colapso metafísico. Nas palavras memoráveis de Horkheimer:

Quando Schopenhauer fala da vida social se refere mais frequentemente às reuniões de sociabilidade (la compagnie, le monde) da sociedade burguesa em seu conjunto; mas quando se trata desta última, é patente seu parentesco com os ilustrados em sentido próprio, muito maior que com Rousseau ou com os românticos, para não falar de Hegel: como as partículas da matéria estão governadas por leis mecânicas, as relações dos indivíduos o estarão por outras psicológicas; e a sociedade consistirá em manter-se unida em virtude dos mecanismos psicológicos do medo e da agressão. (HORKHEIMER, 2018, p. 181) 


\section{Aoristo)))))}

\section{International Journal of Phenomenology, Hermeneutics and Metaphysics}

Ficam, assim, estabelecidas as bases de nossa aproximação entre "distanciamento social" e introspecção. Isto é, se há um vínculo indissociável, para Schopenhauer, entre formação social e afirmação da vontade de vida, tipicamente física e animal, deve haver, por outro lado, um vínculo entre a introspecção e o afastamento social, uma vez que a introspecção está relacionada à necessidade tipicamente metafísica e humana e, consequentemente, à possibilidade de negação da vontade de vida. Contudo, precisamos ainda esclarecer em que sentido tomamos aqui o termo "distanciamento social". Para isso, temos de distingui-lo de outros conceitos médicos com que são frequentemente confundidos pelo público e mesmo pela imprensa ${ }^{3}$.

Distanciamento social é também um outro nome para "distanciamento físico", no qual as pessoas mantêm o espaço de pelo menos 2 metros umas das outras, evitando formação de grupos e aglomerações. O conceito não deve ser confundido com o de quarentena ou de isolamento. Por quarentena deve-se entender a medida de afastar de outras pessoas alguém que poderia ter estado exposto ao vírus, mesmo sem sabê-lo ou mesmo assintomática. Isolamento refere-se ao ato de separar pessoas doentes de pessoas saudáveis, os doentes é que ficam isolados. São conceitos diferentes para a ciência epidemiológica. Nós, contudo, tomamos a expressão "distanciamento social" ou até mesmo "isolamento social" - como incluindo todas essas acepções ao mesmo tempo ${ }^{4}$. Evitar aglomerações, formações em grupo, manter-se fisicamente afastado dos outros, assim como, estando em quarentena ou isolado por motivo de doença, ficar afastado das pessoas saudáveis, todas essas circunstâncias poderiam envolver, a princípio, solidão, angústia, estresse ou introspecção. Contudo, como tencionamos refletir sobre uma circunstância, para todos os efeitos, universal, a respeito da natureza metafísica do homem, não pensamos, aqui, especificamente nos casos de quarentena ou isolamento, mas no caso a que a maioria das pessoas foi ou ainda está submetida, a do distanciamento social. Perguntamo-nos se ela pode, de alguma maneira, relacionarse com uma das condições necessárias e propícias à prática da filosofia e da religião: a introspecção. Porém, perguntamo-nos também, além disso, se o próprio fato em si, a pandemia ela mesma, pode estar relacionado à outra das condições necessárias e propícias a essas práticas: o espanto.

Uma "consciência em face da morte" foi certamente experimentada por quem contraiu, viveu e sobreviveu à COVID-19, por quem, devido a ela, perdeu conhecido, amigo ou ente querido, ou simplesmente por quem acompanha as notícias onipresentes sobre a pandemia; temos presenciado um espanto de proporções globais. Embora o famoso termo aristotélico thaumazein (espanto, Besinnung), de significado filosófico, seja relativamente específico, testemunhos trazem à tona frequentemente esta disposição, seja em virtude do impacto da pandemia na saúde mental, seja através

\footnotetext{
${ }^{3}$ Cf. Social Distancing, Quarantine, and Isolation. CDC - Centers for Disease Control and Prevention, 2020. Disponível em: <https://www.cdc.gov/coronavirus/2019-ncov/prevent-getting-sick/social-distancing.html>. Acesso em: 25 abr. 2020.

4 "Isolamento social" é o termo popularizado na imprensa e, parece-nos, nas conversas pessoais, e não corresponde a nenhum conceito técnico. Talvez porque as pessoas quisessem se referir ao estado geral de desconforto com o isolamento de saudáveis, inclusive com restrição de liberdade, para o qual outros termos não técnicos também são usados, até mesmo "confinamento".
} 


\section{Aoristo)))))}

\section{International Journal of Phenomenology, Hermeneutics and Metaphysics}

dos esforços reiterados de especialistas, chefes de estado e autoridades sanitárias contra o "pânico" injustificado, seja mesmo o explícito recurso ao termo "espanto" (Wonder, Astonishment) como descrição de experiência pessoais. O epidemiologista e diretor do Programa de Emergências da OMS, Michael Ryan, referindo-se ao número de mortos em 24 horas na Itália, afirmou: "É um número espantoso. O fato de que estejam salvando tantos é um milagre em si mesmo" (WHO..., 2020, não paginado). Especialistas em saúde pública dão dicas para que as pessoas permaneçam calmas. (ACHENBACH, 2020) Segundo importante estudo, os maiores efeitos psicológicos negativos da pandemia, as causas de maior estresse sobre a saúde mental, incluem "medos de infecção, frustração, tédio, falta de suprimentos, informações inadequadas, perda financeira e estigma". (BROOKS, 2020) Em alguns casos, o assombro foi tão generalizado a ponto de justificar a publicação de um artigo, com posições de teólogos, para afastar a ideia de que o fim apocalíptico do mundo viria pela pandemia do novo coronavírus. (ZAUMER; BAILEY, 2020)

Schopenhauer (2015b, p. 195) explica que, sem o assombro metafísico, nos assemelharíamos aos demais animais, para os quais "a existência entende-se por si mesma, ao ponto de não a notarem"; e esta seria uma posição invejável, caso fosse acompanhada, como no caso deles, da tranquilidade de quem é guiado pelo instinto, não é atormentado pelo passado e nem se aflige pelo futuro. Mas, no ser humano, isso tudo coexiste. Guiado pela vontade de viver, ele atormenta-se sobretudo com problemas de ordem prática, financeiros, familiares ou de saúde, ao mesmo tempo em que não pode deixar de experimentar a necessidade metafísica que o caracteriza. $\mathrm{Na}$ verdade, problemas de ordem prática não evitam que questões metafísicas também assombrem; entretanto, eles poderiam desviar desse assombro, desestimulá-lo. Tudo depende de se a introspecção será capaz de elaborar o espanto e torná-lo produtivo. Tudo depende de se o conhecimento e a reflexão podem refrear o medo da morte, ou se o desespero, que poderíamos caracterizar como o espanto excessivo sem introspeç̧ão, o atará às urgências do presente.

Quando o conhecimento vence, e por conseguinte o ser humano vai corajoso e sereno de encontro à morte; então esse humano é honrado como grandioso e nobre e festejamos o triunfo do conhecimento sobre a cega Vontade de vida, que, no entanto, é o núcleo de nosso próprio ser. De maneira similar desprezamos o humano no qual o conhecimento é derrotado naquele combate, que, portanto, se apega incondicionalmente à vida, insurgindo-se contra a morte que se aproxima, recebendo-a com desespero: e todavia nele expressa-se apenas a essência originária do nosso si mesmo e da natureza. (SCHOPENHAUER, 2015b, p. 558)

A pandemia e o distanciamento social parecem, sem dúvida, corresponder diretamente às duas condições propícias ao despertamento metafísico. Filosófico, para 


\section{Aoristo)))))}

\section{International Journal of Phenomenology, Hermeneutics and Metaphysics}

os que já têm aptidão [Fähigkeit] específica, e religioso, para os demais. Porém, se o espanto não for acompanhado da devida introspecção, é possível que as pessoas se tornem ainda mais reféns dos impulsos da vontade, desesperando-se pela vida, pela falta de alimentos, de itens de higiene, pelas perdas financeiras. O conflito, particularmente distintivo dessa pandemia, entre as medidas sanitárias e os impactos na economia, é emblemático da cega vontade de viver, que precisa equilibrar diferentes fontes de medo e ameaça. Um fator de estresse extremamente importante aqui é o excesso de informações e a dificuldade de acesso a informações confiáveis.

No início da pandemia na Europa, o filósofo Srećko Horvat (2020) escreveu um artigo intitulado Mais contagioso é o medo 5 . Por outro lado, se o espanto é acompanhado da devida introspecção, é possível também elevá-lo a uma perspectiva de desinteresse, solidariedade e compaixão, virtudes que passam, justamente, pela negação da vontade, frequentemente também afloradas nesta pandemia. A questão, deste modo, parece ser: o que nos pode roubar a introspecção, mesmo em situação de distanciamento ou isolamento social? Certamente a pandemia por si é fonte de espanto. Dadas essas circunstâncias, o que impede que, mesmo distanciado ou isolado, o ser humano se recolha diante de tamanha fragilidade da vida, de tamanha impotência, de modo a assumir uma perspectiva que negue a origem desses medos, a saber, os impulsos da vontade?

Horvat nos oferece uma pista. Embora seu texto tenha conotação fortemente política, há uma série de questionamentos que nos parecem bastante afins à perspectiva schopenhaueriana:

[...] precisamente quando somos bombardeados por imagens distópicas de cidades, aeroportos e navios de cruzeiro em quarentena, e o pânico e a paranoia se espalham rapidamente, é quando precisamos parar e refletir. O surto de um vírus costuma ser o melhor indicador universal do funcionamento de nossas sociedades. Se os sonhos são, nas palavras de Freud, o "caminho real para o inconsciente", um fenômeno global como o surgimento de um patógeno é o caminho real para o inconsciente mundial. [...] Até agora as reações ao coronavírus revelaram menos sobre o microrganismo do que sobre nós mesmos. (HORVAT, 2020, não paginado)

Ele tem em mente, sobretudo, os medos do inconsciente europeu, a relação, muitas vezes preconceituosa, ao Oriente. Mas as primeiras frases da citação acima nos dão uma indicação importante. A hora da introspecção, a hora em que teríamos de parar e refletir, é precisamente quando somos bombardeados por informações, imagens distópicas e, acrescentaríamos, notícias falsas, as chamadas "fake news". Estas, em

\footnotetext{
${ }^{5}$ Horvat é um filósofo croata, autor de "What Does Europe Want? The Union and its Discontents", escrito juntamente com Slavoj Žižek, e de "The Radicality of Love". É um dos fundadores do Movimento Democracia na Europa.
} 


\section{Aoristo)))))}

\section{International Journal of Phenomenology, Hermeneutics and Metaphysics}

contexto de internet e mídias sociais, segundo pesquisa de referência, se propagam mais, e mais rapidamente, do que a verdade 6 :

Somente durante os três dias seguintes à colocação da cidade de Wuhan em quarentena, em 23 de janeiro, mais de 13.000 entradas publicadas no Twitter, Facebook e Reddit difundiam teorias de conspiração sobre a origem do vírus, segundo dados da Storyful, uma empresa que analisa conteúdos das redes sociais, reunidos no site Axios. (HORVAT, 2020, não paginado)

Horvat ressalta, por fim, que certamente o vírus não é "made in China", mas produto do capitalismo global:

Do mesmo modo que, sob os regimes coloniais, as epidemias se espalhavam pelas redes de estradas, ferrovias e canais dos impérios mundiais, o vírus mortal não está se espalhando por culpa da China (não é "chinês"), mas porque nosso mundo nunca esteve tão conectado como hoje. (HORVAT, 2020, não paginado)

Quando estamos a falar de mídias sociais e capitalismo global, queremos dizer que dificilmente o distanciamento físico significa realmente um isolamento social, mas que, pelo contrário, as facilitações técnicas e tecnológicas permitem uma conexão ininterrupta entre os indivíduos, e até mesmo o tráfego intenso de pessoas e mercadorias que esteve na origem do caráter global da atual pandemia. Some-se a isso as novas formas de atividade econômica e especificamente as alternativas usadas pelos países para, durante o problema, evitar prejuízos ainda maiores do que ele já trará, como o tele-trabalho (home office), as aulas pela internet e as "lives" de artistas e personalidades.

Por fim, as dificuldades de gestão da crise sanitária por parte do Estado, em alguns países, cujos chefes de governo passam rumores e boatos como falsas esperanças médicas, aproveitando-se da falta de informações adequadas, provocam crises políticas dentro de crises econômicas que a crise sanitária, por sua vez, já traz. Os indivíduos são bombardeados não só com informações falsas, como também contraditórias. Declarações e atitudes de autoridades são também consideradas "espantosas"; porém, minando a introspecção própria ao conhecimento. A combinação de um fato raro espantoso com o distanciamento social suscetível de

\footnotetext{
${ }^{6}$ Vosoughi et al. usaram um conjunto de dados de cascatas de boatos no Twitter de 2006 a 2017. "Cerca de 126.000 boatos foram espalhados por aproximadamente 3 milhões de pessoas. As notícias falsas chegaram a mais pessoas do que a verdade; o $1 \%$ das principais cascatas de notícias falsas difundiu entre 1.000 e 100.000 pessoas, enquanto a verdade raramente difundiu para mais de 1000 pessoas. A falsidade também se difundiu mais rápido que a verdade. $\mathrm{O}$ grau de novidade e as reações emocionais dos receptores podem ser responsáveis pelas diferenças observadas". (VOSOUGHI et al, 2018)
} 


\section{Aoristo)))))}

\section{International Journal of Phenomenology, Hermeneutics and Metaphysics}

introspecção constitui oportunidade preciosa, embora fácil de esvanecer, de exercício do que é intrinsecamente humano.

Nesse sentido, da perspectiva de Schopenhauer, um exercício inadequado da disciplina filosófica talvez seja aquele demasiado preso à vontade de vida; ou aqueles, demasiadamente críticos ou céticos, que deixam escapar a coisa em si, a Vontade, da qual a morte, a miséria e o sofrimento nos fazem saber. Os relativismos ou as ênfases entusiasmadas no ideológico, além disso, parecem não se refletir o fato de que uma determinada realidade se impõe. Talvez resida aqui um tipo de introspecção, ou reflexão, sobre algo que não mais espanta o suficiente, e do qual nasce, para Schopenhauer (2015b, p. 209), a metafísica, a saber, "a visão do mal e do mau no mundo". Pois

[...] o mau, o mal e a morte são o que qualificam e elevam ao filosófico: não simplesmente que o mundo exista, mas antes que seja tão sombrio, eis o punctum pruriens da metafísica, o problema que coloca a humanidade numa inquietude que não pode ser aliviada por ceticismo nem por criticismo. (SCHOPENHAUER, 2015b, p. 210)

O sofrimento é a crítica da crítica. Na verdade, é até mesmo um enigma pensar que se possa filosofar de modo tão alvissareiro, pois "se nossa vida fosse sem fim nem sofrimento, talvez a ninguém ocorresse perguntar por que o mundo existe e por que tem precisamente essa índole; porém, tudo se entenderia por si mesmo". (SCHOPENHAUER, 201b, p. 196) Por isso, é mesmo de se perguntar se a presente pandemia pode ser tomada como a chance de uma nova abertura metafísica da filosofia, pois em nenhum outro fato da vida a essência íntima do mundo se impõe de modo mais dramático sobre as nossas opiniões.

A maior probabilidade, entretanto, ainda na perspectiva schopenhaueriana, de que as prerrogativas da metafísica sejam aplicadas de modo nocivo está do lado das religiões; isso se seguirmos a distinção que o autor faz entre elas, "as doutrinas da fé", e as diferentes filosofias, também classificadas por ele como "doutrinas da persuasão". Estas "exigem reflexão, formação, esforço e juízo para o reconhecimento da sua certificação", ou seja, não são aceitas sem deliberação, e "só podem ser acessíveis a um reduzidíssimo número de pessoas" (SCHOPENHAUER, 2015b, p. 201), logo, tem o seu campo de ação bastante limitado. Já as religiões têm maior potencial para causar impactos porque são direcionadas a uma quantidade muito maior de pessoas, e que está bem mais disposta a acreditar do que a refletir, "receptiva não às razões, mas apenas à autoridade [...]"; até porque elas têm sua certificação exterior a si, na "revelação", "documentada através de signos e milagres". (SCHOPENHAUER, 2015b, p. 200)

Mais ainda, a "doutrina da fé" é ensinada já às crianças, "com o que os seus dogmas florescem como uma espécie de segundo intelecto inato, igual às ramas enxertadas numa árvore [...]", tornando a influência deles quase que inabalável; as filosofias, por seu turno, dirigem-se "sempre apenas aos adultos" e "nestes sempre já encontram um sistema do segundo tipo [religioso] na posse das suas convicções". 


\section{Aoristo)))))}

\section{International Journal of Phenomenology, Hermeneutics and Metaphysics}

(SCHOPENHAUER, 2015b, p. 200) Com base nisto, as doutrinas da persuasão se fazem muito menos presentes do que as doutrinas da fé. Outra prova disso é, segundo Schopenhauer (2015b, p. 201), que "os povos se diferenciam e são separados mais segundo eles [os diferentes tipos de religiões] do que segundo a nacionalidade, ou a forma de governo". Por isso, chega mesmo a questionar por que, às vezes, a religião requer "o acordo dos pobres filósofos" (SCHOPENHAUER, 2015b, p. 202), que poderiam ser inteiramente dispensáveis.

Contudo, também certos usos da religião estão cingidos de uma metafísica superficial, de seu aspecto mais básico, a imortalidade, quando são apenas, e manifestamente, a mais desesperada e urgente afirmação da vontade de viver. Pois:

[...] se o dogma da imortalidade pudesse ser-lhes assegurado de outra maneira, então o vivo zelo por seus deuses esfriaria de imediato, e, por outro lado, se se pudesse demonstrar-lhes a completa impossibilidade de uma imortalidade, aquele zelo daria lugar a uma total indiferença: pois o interesse na existência dos deuses desapareceria com o desaparecimento da esperança de uma familiaridade mais íntima com eles, a não ser naquele resto em que se poderia atribuir aos deuses uma possível influência sobre os acontecimentos da vida presente. [...] Sobre o mesmo fundamento baseia-se o fato de os sistemas

Certamente o interesse e a reflexão sobre a imortalidade podem transportar para um registro que ultrapassa o mundo fenomênico, com todas as suas dores e sofrimentos, e no qual impera a vontade cega. Entretanto, uma vez que Schopenhauer julga mesquinha a afirmação da vontade, o "segundo motivo", por assim dizer, de interesse pelas religiões, isto é, a "possível influência sobre os acontecimentos da vida presente", talvez seja menos metafísica, e na verdade bastante vulgar. Não poderíamos esboçar aqui, nestes termos, uma crítica à teologia neopentecostal da prosperidade? Também às espiritualidades baseadas na técnica, no modo mágico de manipulação de forças míticas, que até mesmo comem e bebem? É preciso saber reconhecer o cerne metafísico das religiões. Não a prosperidade na vida, mas o consolo na morte inevitável, em primeiro lugar. Não o egoísmo e as falsas esperanças, mas a caridade e a compaixão, que são "sempre e tão somente o CONHECIMENTO DO SOFRIMENTO ALHEIO”. (SCHOPANHAUER, 2015a, p. 435-436 [maiúsculas do autor]).

É verdade que a definição schopenhaueriana de amor como compaixão, sua tese de que os sofrimentos são essenciais à vida, e de que todo bem é negativo, e mera ausência de sofrimento, o conduzem ao cristianismo, que teria apresentado à Europa virtudes desconhecidas dos antigos (SCHOPENHAUER, 2009, p. 360-361), talvez mesmo a certo monergismo, isto é, à tese de que "ao homem enquanto tal só sejam

Arthur Grupillo

Matheus Freitas

Toledo, v. 3, n’2(2020) p. 27-40 


\section{Aoristo)))))}

\section{International Journal of Phenomenology, Hermeneutics and Metaphysics}

possíveis ações pecadoras, isto é, egoístas". (DEUSSEN, 2013, p. 136) Porém, como a "necessidade metafísica não anda de mãos dadas com a capacidade metafísica" (SCHOPENHAUER, 2015b, p. 197), já o sabemos, isso significa que nem tudo aquilo, ou melhor, nem todo aquele que visa arrebatar as consciências humanas do mundo dos fenômenos empíricos é capaz de transportá-las a um estado melhor ou mais nobre que este. $\mathrm{O}$ autor refere-se ao que podemos chamar de mercadores de metafísicas, "tipos que se esforçavam em tirar o seu sustento daquela necessidade metafísica do ser humano e explorá-la ao máximo [...]”. (SCHOPENAHUER, 2015b, p. 198)

Não foram tipos assim que, diante das recomendações de distanciamento e fechamento do comércio, durante a pandemia, se lançaram a reivindicar a abertura de seus templos ou mesmo a manutenção, sem restrição, de seus cultos, defendendo o serviço religioso como essencial? Mas, se o que é realmente essencial à religião é o consolo metafísico e o sacrifício do amor próprio em benefício da compaixão caridosa, em suma, a viragem da afirmação para a negação da vontade, não resultaria o distanciamento numa maior consciência da morte, numa maior introspecção e no entendimento do encontro social não como confluência de interesses, mas, pelo contrário, confluência de humildades, paciências e renúncias? Não estariam estes tipos, além disso, ao enfatizar como essencial o que não é essencial na religião, opondose a decisões que devem mais apropriadamente ser tomadas pelas ciências? Se bem que também estas, para Schopenhauer, encontram-se limitadas em seu materialismo, quando comparadas às necessidades genuinamente metafísicas, estas sim, essenciais.

Aqui, uma interessante tese parece vir à tona. Se a necessidade metafísica exercitada na religião pode degenerar no contrário e, guiada por falsos profetas, tornar-se comércio e afirmação desesperada da vida, poderá também entrar em conflito com a ciência, caracterizada por Schopenhauer como um saber voltado às satisfações da vontade de viver. Diferentemente, contudo, a introspecção tipicamente filosófica significa "conhecer não apenas para satisfazer as necessidades momentâneas da vontade individual, para servi-las nas urgências do presente". (SCHOPENAHUER, 2015b, p. 681) As ciências, portanto, também míopes a respeito da destinação metafísica do homem, que a boa prática da religião, por sua vez, guarda, devem ser contidas e delimitadas, assim como os maus exercícios da religião, por uma metafísica propriamente filosófica.

Para Schopenhauer, uma excelente aliada da religião, enquanto prática metafísica adequada, contra sacerdotes mal-intencionados é a filosofia, desde que uma não recorra à outra como mero instrumento para certificar suas proposições. Neste sentido, a filosofia contribui tanto para domar os excessos de líderes religiosos deste tipo quanto para proteger a própria religião dos avanços das ciências naturais, que cada vez mais despontam como as únicas encarregadas de sondar os mistérios do mundo:

[...] deve-se ademais considerar que [...] [a filosofia] prestou o inestimável serviço de colocar limites às infinitas exigências da metafísica privilegiada [isto é, da religião em geral] e atuar ao mesmo tempo contra o naturalismo e materialismo propriamente ditos que 


\section{Aoristo)))))}

\section{International Journal of Phenomenology, Hermeneutics and Metaphysics}

surgiram como inevitável reação àquela. (SCHOPENHAUER, 2015b, p. 227)

Nesta passagem, Schopenhauer não apenas ressalta os ganhos da coexistência entre as reflexões filosóficas e as genuinamente religiosas; ele pontua que essas duas bandeiras da metafísica devem, apesar dos avanços das teorias naturalistas e materialistas em suas explicações da natureza, manter-se firmes em sua tarefa de acolher a carência metafísica humana. E isso fica ainda mais claro mediante uma comparação, feita por Schopenhauer, entre os objetos das ciências e o da metafísica. Esta tem como objeto de reflexão aquilo que, em meio à realidade dos fenômenos constitutivos de nossa experiência, se afigura como universal; as ciências, ao contrário, num procedimento inverso, tomam como objetos de estudo fenômenos bem delimitados e criteriosamente escolhidos. (SCHOPENHAUER, 2015b, p. 196) Assim, graças às ciências "vemos hoje em dia a casca da natureza com a maior exatidão, os intestinos dos vermos intestinais e os parasitas dos parasitas serem conhecidos em detalhe". (SCHOPENHAUER, 2015b, p. 217) Em nosso contexto, testemunhamos o esforço dos cientistas nos seus meticulosos estudos de sequenciamento genético para encontrar curas específicas para a COVID-19 ou a vacina adequada contra seu vírus. Mas, na esfera metafísica, os problemas são universais, não restritos às circunstâncias da pandemia, e, portanto, tocam diretamente a questão dos rumos que a humanidade pode seguir após essa crise: se o egoísmo e o individualismo não precisam, de algum modo, ser equilibrados por relações humanas mais solidárias e compassivas. Entretanto, também essa esperança parece ser excessiva para uma metafísica de Vontade tão sombria quanto a de Schopenhauer. Aqui, encontramos ocasião para uma crítica, além de uma conclusão.

Convém questionar, depois de tudo, as limitações da própria concepção schopenhaueriana de metafísica. Não haveria outro espaço para a esperança, a não ser aquela post mortem, ensinada pelas religiões? Não se tem outra esperança nas ciências, a não ser a de uma facilitação técnica das afirmações egoístas da vontade? Será mesmo, além disso, que todas as religiões dão de costas ao mundo dos fenômenos? São Francisco de Assis, por quem Schopenhauer tem enorme admiração pelo ímpeto de negação da vontade, certamente falava "irmão asno", referindo-se ao próprio corpo; mas também não dizia "irmão sol, irmã lua"? A boa metafísica bem poderia estar no fato de que nós, exercitados na consciência da essência tenebrosa do mundo, teimamos em ir além dela. Não falamos aqui de falsas esperanças. Por causa da pandemia, alguns diziam que cisnes teriam voltado aos canais de Veneza, patos, aos lagos de Roma, golfinhos, ao porto de Cagliari. É sem dúvida demasiado representar um mundo que supera, da noite para o dia, sua essência sombria. Mas será boa metafísica aquela que se aferrou apenas à parte da história que afirma ser o homem "o principal dos pecadores", e não também "a principal das criaturas", precisamente a única capaz de espanto e introspecção? 


\title{
Aoristo)))))
}

\author{
International Journal of Phenomenology, Hermeneutics and Metaphysics
}

\section{REFERÊNCIAS}

ACHENBACH. J. Mental health experts offer counsel on staying calm during coronavirus pandemic. The Washington Post, 17 marc. 2020.

BROOKS, S. et al. The psychological impact of quarantine and how to reduce it: rapid review of the evidence. In: Lancet. Vol. 395, 2020, p. 912-20. DOI: https://doi.org/10.1016/S0140-6736(20)304608.

DEUSSEN, Paul. Schopenhauer e a religião. Trad. Guilherme Marconi Germer. In: Voluntas: Revista Internacional de Filosofia. Vol. 4, no 1, 1ㅇs semestre 2013, p. 131-138.

HORKHEIMER, M. "Schopenhauer e a sociedade". Trad. Thiago Souza Salvio. In: Voluntas: Revista Internacional de Filosofia. Vol. 9, n. 2, p. 180-189, jul.-dez. 2018.

HORVAT, SREĆKO. Mais contagioso é o medo. El País Internacional, 2020. Disponível em:

$<$ https://brasil.elpais.com/internacional/2020-02-16/mais-contagioso-e-o-medo.html>. Acesso em: 30 abr. 2020.

SCHOPENHAUER, A. O mundo como vontade e como representação, primeiro tomo. Trad. Jair Barboza. 2o ed. São Paulo: Editora Unesp, 2015a.

.O mundo como vontade e como representação, segundo tomo: suplementos aos quatro livros do primeiro tomo. Tradução, apresentação, notas e índices de Jair Barboza. São Paulo: Editora Unesp, 2015b.

. Parerga y Paralipómena II. Trad. Pilar Lopez de Santa Maria. Madrid: Trotta, 2009.

SOCIAL Distancing, Quarantine, and Isolation. CDC - Centers for Disease Control and Prevention, 2020. Disponível em: <https://www.cdc.gov/coronavirus/2019-ncov/prevent-getting-sick/socialdistancing.html>. Acesso em: 25 abr. 2020.

VOSOUGHI, S; ROY, D.; ARAL, S. The spread of true and false news online. In: Science. Vol. 359, issue 6380, mar. 2018, p. 1146-1151.

WALKER, P. et al. The Global Impact of COVID-19 and Strategies for Mitigation and Suppression. In: Imperial College London, 2020. DOI: https://doi.org/10.25561/77735.

WHO: Testing, tracing must be 'backbone' of coronavirus response. Al jazeera, 2020. Disponível em: $<$ https://www.aljazeera.com/news/2020/03/testing-tracing-backbone-coronavirus-response200318191010542.html>. Acesso em: 30 abr. 2020.

ZAUZMER, J. BAILEY, S. P. This is not the end of the world, according to Christians who study the end of the world. The Washington Post, 17 mar. 2020.

Submetido: 2 de outubro de 2020

Aceito: 2 de novembro de 2020

Necessidade metafísica e distanciamento social por pandemía 